\title{
NEW WEIRD E LITERATURA BRASILEIRA: ANÁLISE DO CONTO MENINA BONITA BORDADA DE ENTROPIA, DE CIRILO LEMOS
}

NEW WEIRD AND BRAZILIAN LITERATURE: AN ANALYSIS OF THE SHORT STORY MENINA BONITA BORDADA DE ENTROPIA, BY CIRILO LEMOS

Cristhiano Aguiar André Karasczuk Taniguchi 
RESUMO: O presente artigo busca compreender o New Weird, vertente da literatura insólita originada em literaturas de língua inglesa entre o fim da década de 1990 e começo dos anos 2000. Para tanto, além de uma revisão teórica sobre o New Weird, buscaremos entender a sua recepção na literatura brasileira, por meio da leitura do conto "Menina bonita bordada de entropia", de Cirilo Lemos, publicado na antologia Fractais tropicais: $o$ melhor da ficção científica brasileira, organizada por Nelson de Oliveira.

PALAVRAS-CHAVE: New weird; Cirilo Lemos; horror; Ficção científica; Literatura brasileira.

ABSTRACT: This paper attempts to comprehend the New Weird, a strand of Fantasy literature originated in English literatures during the late 90s and beginning of 00s. Besides a theoretical review about the New Weird, we will look for its reception in Brazilian literature by analyzing the short story "Menina bonita bordada de entropia", by Cirilo Lemos, published in the anthology Fractais Tropicais: o melhor da ficção científica, organized by Nelson de Oliveira.

KEYWORDS: New weird; Cirilo Lemos; Horror; Science fiction; Brazilian literature. 


\section{NEW WEIRD: PERSPECTIVAS DE DEBATE}

Em meio à vertigem terminológica que às vezes toma conta das discussões relacionadas ao fantástico e ao insólito ${ }^{3}$, o termo New Weird possui uma presença ainda tímida tanto nos debates universitários brasileiros, quanto em nosso mercado editorial. Não apenas há poucos estudos sobre o tema, como também existem parcas traduções das principais antologias e romances muitas vezes tachados como pertencentes a este subgênero. Um exemplo é a ausência de um debate sobre o New Weird no mais amplo panorama, publicado até o momento, sobre a história da literatura insólita nacional. Referimo-nos à obra Fantástico brasileiro: o insólito literário do romantismo ao fantasismo, de autoria dos escritores e pesquisadores Bruno Anselmi Matangrano e Enéias Tavares, originalmente publicada em 2018.

Como é sugerido por Mendlesohn e James (2009, p. 151), o New Weird, como logo mais será debatido, surge no contexto da literatura anglófona - em especial no Reino Unido - no fim dos anos 1990 e começo dos anos 2000, e se propõe a ser um ponto de cruzamento das principais tendências contemporâneas do insólito. Além de misturar elementos da Fantasia, da Ficção Científica e do Horror, o gênero muitas vezes contém influências da Literatura Policial, do Surrealismo e até mesmo do Realismo Maravilhoso.

Buscando ampliar as fronteiras do insólito, autores como China Miéville e Jeff VanderMeer produziram, em obras como Aniquilação (VANDERMEER, 2014), ou A cidade e a cidade (MIÉVILLE, 2014), algumas das mais instigantes e inclassificáveis narrativas da literatura contemporânea. Parece haver altas pretensões no New Weird - para o bem e para o mal. Acolhendo um registro de maior experimentação poética e estilística, bem como assumindo para si a proposição de debates políticos, o New Weird trilha, ao menos na prosa de ficção, um caminho próprio que oscila entre a

3 A partir de agora, vamos utilizar o termo "literatura insólita" para designar o conjunto de narrativas que não se pauta pela representação consensual de uma realidade cotidiana, ou seja, contos, narrativas e novelas que não possuem o registro do Realismo como dominante estética. O termo literatura insólita, portanto, é o sentido mais amplo que agrega diferentes vertentes como o Horror, a Ficção Científica, a Fantasia ou a Literatura Fantástica, por exemplo. 
complexidade da procura pela elaboração literária sem concessões e o apelo ao popular "sense of wonder" (senso de admiração ou maravilhamento) tão comum na Fantasia e na Ficção Científica, por exemplo.

Seja por influência direta destas obras, ou por uma convergência de afinidades, analisar uma série de narrativas da cultura pop recente através da perspectiva da New Weird pode ser um exercício fecundo. No campo dos videogames, por exemplo, sucessos recentes como os jogos da franquia Bioshock, que apresentam um amálgama de ficção científica, paródia política, distopia e horror, ou Death Stranding, no qual encontramos esses mesmos elementos, nos fazem pensar se não estamos diante de games do New Weird.

Desde meados dos anos 1980 e 1990, muitas histórias em quadrinhos podem ser compreendidas numa clave semelhante. Quadrinhos como Sandman, de Neil Gaiman, Os invisíveis, de Grant Morrison, Moonshadow, de J.M Dematteis e J.J. Muth, ou Gideon Falls, de Jeff Lemire e Andrea Sorrentino, são exemplos possíveis. Todos possuem um denominador comum: a presença de elementos do Horror, do insólito, de situações surreais ou extremamente avançadas tecnologicamente.

Na TV, um seriado como Lovecraft Country, com suas discussões raciais perpassando um mundo de Fantasia e Horror, pode vir à nossa mente como um possível exemplo, no audiovisual, do New Weird. E, ainda no campo da TV, quem sabe a matriz de todas as estranhezas audiovisuais das telinhas, o seriado Twin Peaks, não seria também classificável como um precursor do gênero?

Nossos exemplos têm se pautado por obras oriundas dos Estados Unidos e Reino Unido. Podemos identificar traços do New Weird no Brasil? Esta é a pergunta que este artigo faz. Defendemos que ao menos um romance brasileiro, nos últimos anos, se aproxima deste gênero: Exorcismos, amores e uma dose de blues, escrito por Eric Novello. O foco do presente artigo, no entanto, não é o romance de Novello, mas sim alguns contos publicados em uma importante antologia de ficção científica nacional. Fractais tropicais: o melhor da ficção científica brasileira, organizada pelo escritor Nelson de Oliveira (2018), vem se somar a outras antologias dedicadas à Ficção Científica (FC) nacional, entre elas aquelas organizadas por Causo e Tavares, por exemplo. Antologizando contos de diferentes perfis autorais e tendências, escritos por 
representantes das diferentes gerações da nossa FC, Oliveira aponta como pertencentes ao New Weird cinco contos da sua própria publicação. São eles "Menina bonita bordada de entropia”, de Cirilo Lemos, "Los cibermonos de Locombia”, de Ronaldo Bressane, “Galimatar”, de Fábio Fernandes" , “O dia em que Vesúvia descobriu o amor”, de Octavio Aragão, e "Caro senhor Armagedon", de Fausto Fawcett. Para o escopo deste artigo, analisaremos somente um desses contos, aquele que consideramos mais próximo do New Weird: "Menina bonita bordada de entropia", de Cirilo Lemos. O segundo conto que consideramos, dentre os cinco listados, mais próximo do New Weird, de autoria de Bressane, será discutido em um próximo artigo.

New Weird nos parece um termo que ajuda a compreender cada um dos contos, em especial no caso de Cirilo Lemos. Por outro lado, achamos perfeitamente possível vincular um mesmo texto literário a diferentes correntes estéticas, caso haja nele elementos suficientes que estabeleçam um bom diálogo com pressupostos teóricos previamente colocados pelo pesquisador da área. Desta forma, New Weird é, aqui, muito mais uma lente de análise do que uma categoria definitiva que esgotaria as potencialidades de intepretação das narrativas da antologia.

\section{SOBRE O NEW WEIRD: ORIGENS E PERSPECTIVA TEÓRICA}

Como apontamos, o New Weird é um subgênero da Fantasia relativamente recente, sendo sua primeira manifestação literária o romance Perdido Street Station, de China Miéville, publicado em 2000 (traduzido no Brasil como Estação Perdido, em 2016). Jeff VanderMeer, outro importante autor do gênero, em The New Weird (2008), assim o define:

New Weird é um tipo de ficção urbana ou de mundo secundário que subverte as ideias romantizadas de espaço encontradas na

4 Fábio Fernandes é tradutor de alguns escritos de China Miéville, inclusive Estação Perdido (2016), um dos romances considerados como inaugurais do New Weird. 
Fantasia tradicional, principalmente ao escolher modelos realistas e complexos do mundo real como ponto de partida para a criação de ambientações que podem combinar elementos tanto da Ficção Científica quanto da Fantasia. O New Weird possui uma qualidade visceral que frequentemente utiliza elementos surreais ou do horror transgressivo para seu tom, estilo e efeitos [...] Ficções do New Weird são intensamente conscientes do mundo moderno, mesmo quando disfarçadas, mas não são sempre abertamente políticas. Como parte dessa consciência do mundo moderno, o New Weird, para seu poder visionário, depende de uma "rendição ao estranho", que não é, por exemplo, exclusiva a uma casa assombrada num pântano ou em uma caverna na Antártida. (VANDERMEER, 2008, pp. xvi, tradução nossa). ${ }^{5}$

Em outras palavras, o New Weird frequentemente cria universos urbanos, mesclas do real com o fictício, e enriquece estes mundos com seres, elementos e temas surreais ou provenientes da Fantasia, do Horror e da Ficção Científica. São realidades conscientes do mundo moderno, apesar de não necessariamente serem panfletárias em um caráter político.

No verbete acerca do subgênero da Encyclopedia of Science Fiction (versão online), lê-se: "Histórias do New Weird misturam livremente estratégias da FC [Ficção Científica], da Dark Fantasy e do Horror"6 [tradução nossa]; apesar de mais aspectos comporem as principais características do New Weird, destacamos a principal para esta introdução. Esse subgênero consiste na combinação de diversos traços da Fantasia

5 New Weird is a type of urban, secondary-world fiction that subverts the romanticized ideas about place found in traditional fantasy, largely by choosing realistic, complex real-world models as the jumping off point for creation of settings that may combine elements of both science fiction and fantasy. New Weird has a visceral, in-the-moment quality that often uses elements of surreal or transgressive horror for its tone, style, and effects [...] New Weird fictions are acutely aware of the modern world, even if in disguise, but not always overtly political. As part of this awareness of the modern world, New Weird relies for its visionary power on a “surrender to the weird" that isn't, for example, hermetically sealed in a haunted house on the moors or in a cave in Antarctica. (VANDERMEER, 2008, pp. xvi).

6 “New Weird stories freely mingle sf [science fiction], dark Fantasy and Horror tropes". Disponível em: <http://www.sf-encyclopedia.com/entry/new_weird>. Acesso em: 15 mar. 2021. 
e da Ficção Científica; no entanto, é fundamental que suas histórias possuam temas ou elementos que transmitam um efeito horrorizante, ou seja, que tragam consigo situações e acontecimentos bizarros, ou talvez repugnantes, principalmente se essas situações tiverem sua origem a partir da transfiguração, mutação ou mutilação de corpos, ecoando um efeito do Horror.

Dessa forma, podemos dividir o New Weird em quatro "pilares" fundamentais, os quais auxiliam na análise de textos do subgênero: combinação de gêneros, aspectos grotescos, ênfase no espaço (principalmente o urbano) e a presença de algum discurso político. Discorreremos a seguir sobre esses quatro pilares.

A Encyclopedia of Science Fiction (versão online) aponta que o New Weird mistura Fantasia, Horror e Ficção Científica livremente. No entanto, o subgênero vai além da mescla inicial e parte para a combinação de mais gêneros e subgêneros, construindo mundos secundários bastante diversos. Assim, é possível afirmar que o New Weird permite inúmeras combinações de gêneros e subgêneros, mas sempre mantendo uma característica fundamental: imagens grotescas, um elemento comum às narrativas de Horror. Em decorrência, esse elemento do Horror sempre estará presente, de alguma forma, nas narrativas New Weird, enquanto a presença e a combinação de outros gêneros ou subgêneros variará de acordo com o texto.

Ressaltamos que, ao utilizarmos o termo "grotesco", não nos referimos ao grotesco como concebido por Bakhtin em A Cultura Popular na Idade Média e no Renascimento (2010), cujo conceito baseia-se em uma perspectiva acerca do plano material, corporal; nossa perspectiva de grotesco é embasada em uma outra interpretação da palavra, assemelhando-a a termos como nojento, repugnante, bizarro etc. Malcolm-Clarke, em um artigo para a antologia The New Weird (2008) discorre acerca dessa concepção de grotesco:

O que é o grotesco? Primeiramente, é um registro estético que perturba. Considere a gárgulas, a Medusa, o monstro de Frankenstein, o alien nos filmes de mesmo nome. $O$ sangue e as entranhas em algum filme de horror sugere ansiedade na tentativa de aceitar a morte. Mas o grotesco aponta a algo totalmente diferente, algo mais sutil. É um desconforto que sugere que nosso modo de classificar o mundo em partes conhecidas não é o suficiente; o grotesco é, fundamentalmente, 
confusão, porque partes distintas de algo não fazem sentido juntas. $\mathrm{O}$ grotesco demonstra que existem coisas para as quais não possuímos categorias, e, portanto, que nosso modo de construir significado é artificial. (MALCOLM-CLARKE, 2008, p.339, tradução nossa) ${ }^{7}$

Ainda sobre o grotesco, levamos em conta as considerações do escritor e teórico espanhol David Roas (2014). Segundo ele, “o grotesco, por sua vez, é uma categoria estética baseada na combinação do humorístico com o terrível" (ROAS, 2014, p.190). Desta maneira, as expressões do grotesco, ao longo do tempo, desenvolvem-se pendendo para um dos extremos deste espectro: "poderíamos chamar de eixo do grotesco, que teria em uma das extremidades o grotesco puramente festivo [...] e na outra sua versão mais sinistra" (ROAS, 2014, p.191). No caso do New Weird, pensamos que o grotesco se faz presente nas duas modalidades, embora com predominância do seu aspecto sinistro, na linha de Roas e Malcolm-Clarke. Isto é bem representado nos contos de Lemos e Bressane. Ao passo que Lemos cria uma narrativa voltada ao Horror e à decomposição corporal, Bressane constrói um grotesco mais carnavalizado e bem-humorado, que pode ser melhor lido pela perspectiva Bakhtiniana, por exemplo. $\mathrm{O}$ acúmulo de situações inverossímeis, em Bressane, amplificadas pelo humor da linguagem de seu conto, somada ao uso linguístico de um "portunhol" exagerado, tensionam a base de Ficção Científica da narrativa ao ponto de quase implodi-la em uma Paródia. Ainda assim, no caso de Bressane, a ausência da mistura de gêneros é contrabalançada pelo grotesco humorístico em alta voltagem, elemento este que, conciliando o cômico, comentário político, pitadas surrealistas e especulação selvagem, posiciona-o no New Weird.

Nesse sentido, o grotesco é perturbador na mesma medida em que é confuso,

7 What is the grotesque? For one thing, it's an aesthetic register that unsettles. Consider gargoyles, Medusa, Frankenstein's monster, the alien in the movies of the same name. The out-and-out blood and guts of some kind of splatter-oriented horror suggests anxiety about the attempt to come to grips with death. But the grotesque point to something else entirely, something more subtle. It's an unease that suggests our way of classifying the world into knowable parts doesn't get the job done; it is, ultimately, confusion, because the different parts of something don't make sense together. The grotesque demonstrates that there are things for which we do not have categories, and, therefore, that our ways of making meaning are artificial. (p.339) 
que apresenta algo desconfortável, por vezes desconhecido e desprovido de um sentido consolidado. Esse conceito é frequente no Horror, principalmente no cinema, o qual possui um subgênero específico chamado Gore ${ }^{8}$ (palavra esta que também pode ser utilizada para se referir a elementos grotescos), e é emprestado pelo New Weird, porém, sem o efeito do medo. Malcolm-Clarke (In: VANDERMEER, 2008, p.338) argumenta que o grotesco no New Weird possui a funcionalidade do exagero, é uma parte do mundo secundário, e parte fundamental da estética geral do subgênero.

Também no verbete sobre o New Weird na Encyclopedia of Science Fiction (versão online), uma das primeiras definições apresentadas é a predominância da ambientação urbana nas narrativas do subgênero ${ }^{9}$. Embora a presença do ambiente urbano não seja uma regra absoluta, como pode ser evidenciado pelo romance Aniquilação (2014), de Jeff VanderMeer - o qual é ambientado em um cenário selvagem, fora do domínio humano -, é possível supor que toda narrativa New Weird possuirá alguma questão social ou política que provavelmente estará diretamente relacionada com contextos de convívio social contemporâneo. Nesse sentido, a ambientação se torna fundamental para a construção de um universo coeso, imersivo, que de alguma forma dialoga com questões sociais ou problemas do mundo contemporâneo, mesmo que nem sempre de forma panfletária.

\section{NEW WEIRD: OS CONTOS DA ANTOLOGIA FRACTAIS TROPICAIS}

Dentre os títulos nacionais apresentados neste artigo, sem dúvidas, aquele que mais corresponde aos atributos apresentados durante a fundamentação teórica

8 O gore pode ser considerado mais próximo de uma categoria estética do que um subgênero em si, uma vez que os percursos narrativos nesses tipos de filmes podem trilhar diversos caminhos; o gore, na verdade, refere-se, principalmente, à exploração explícita da desfiguração, mutilação, mutação, entre outros recursos grotescos auxiliados pelos efeitos especiais do cinema.

9 “Ambientações complexas em cenários urbanos sujos e noir, e um apego pelo grotesco são características [do New Weird], mas não necessariamente qualidades definidoras." [tradução nossa]. Disponível em: <http://www.sf-encyclopedia.com/entry/new_weird>. Acesso em: 15 mar. 2021. 
do subgênero New Weird é o conto "Menina bonita bordada de entropia”, do escritor carioca Cirilo Lemos. O texto é, além disso, o mais inclassificável de toda a antologia organizada por Nelson de Oliveira, a ponto de ser um conto que poderia, de maneira confortável, aparecer em uma antologia de Horror ou de Fantasia nacional. Especulação científica, robôs, demônios, magia e buracos negros se misturam no conto de Lemos. Além do mais, o conto, em cada um dos seus parágrafos, cria cenas sempre preocupadas em acentuar um tom insólito, desconfortável, estranho. Por fim, chama atenção a presença de elementos típicos do Horror, tais como o gore, a fragmentação dos corpos, referências ao ocultismo e a uma estética grotesco-sinistra, em especial no caso da caracterização das suas personagens.

O enredo do conto se desenvolve em poucas horas. Um ser chamado somente de Menininha se encontra preso no fundo do oceano. Quem ela é? O conto não nos explica, porém dá a entender que seria alguma forma de vida artificial, de origem mágica e/ou científica. O leitor é levado a pensar assim porque Menininha não é um apelido exclusivo da personagem; pelo contrário, parece ser uma terminologia usada para se referir a alguma forma de existência, a alguma classe de seres dotados de autoconsciência, da qual a personagem em questão faz parte. Embora esteja acorrentada no fundo do oceano, a protagonista não precisa respirar embaixo d'água. Sua única necessidade física, além do desejo de se libertar, consiste em um apetite voraz. A fome que ela sente é um traço fundamental da personagem e significativo para o desfecho súbito e violento do conto. Ao aparecer pela primeira vez, a fome, somada à capacidade de a Menininha respirar embaixo d'água, cria uma profunda sensação de estranheza na narrativa:

Daí começou a chorar, pois é isso que Menininhas fazem quando estão assustadas. [...] Só quando se cansou de chorar e de imaginar destinos para as lágrimas foi que percebeu: não havia respirado uma única vez desde que abrira os olhos. [...] Um peixe quer me comer, a Menininha pensou. Ela amava os animais. [...] O peixe arriscou uma quarta mordida, mas com um movimento rápido ela o abocanhou e o esmagou entre os dentes. Engoliu o que foi possível linfa, carne, escama e espinha (LEMOS, 2018, p.71-72) 
Contrastes são estabelecidos. Primeiro, pela imagem, estranha em si: uma criança acorrentada no mar agarra um peixe e o devora de maneira voraz. O impacto é causado, de igual forma, por uma bem dosada técnica de contraste. Afinal, até que o peixe morresse, tínhamos entendido que: a) a Menininha é uma vítima e está em uma situação de perigo, portanto ao seu redor se constrói um halo de inocência; b) a Menininha possui uma natureza milagrosa, ela respira embaixo d'água (o que não necessariamente é tão chocante assim, dada a natureza da antologia na qual o conto foi publicado). Com o ataque ao peixe, acrescenta-se uma dimensão agressiva à criança que contrasta com a imagem da personagem esboçada nos pontos a) e b).

Não devemos, além de tudo, subestimar a função do narrador desta história. Cirilo Lemos utiliza um narrador onisciente em terceira pessoa, permitindo que o leitor tenha uma dimensão mais panorâmica a respeito da construção do universo insólito do conto, que, por sua natureza concisa, precisa aproveitar o máximo de recursos de construção de mundo nas poucas páginas que possui. A característica mais digna de nota, no entanto, é a utilização do discurso indireto livre por parte deste narrador. A todo o momento, a narrativa se deixa "contaminar" pelos pensamentos e pelas emoções da personagem aprisionada. No trecho destacado, o discurso indireto livre na sentença "Daí começou a chorar, pois é isso que Menininhas fazem quando estão assustadas". Qual a sua função? Dar um tom de ingenuidade a uma narrativa bastante sombria em sua imagética. Assim, a tensão entre ingenuidade e estética obscura cria um dos maiores pontos de interesse na leitura de "Menina bonita bordada de entropia".

O momento de consolidação do estilo New Weird no conto deflagra-se quando a Menininha é pescada por um navio. Aqui, ocorre o encontro entre o Horror e a Ficção Científica, uma vez que o navio é comandando por um robô, mas a sua tripulação é formada por grotescos e sujos demônios. Tal combinação pode soar estranha à literatura, em especial à literatura brasileira ${ }^{10}$ - o seu sentido mais realista. Contudo,

10 Como argumentado por Causo (2003), a literatura brasileira possui uma predileção histórica pelos temas realistas, demonstrando uma espécie de "rejeição canônica” aos elementos insólitos, principalmente a partir do século XIX. 
é frequente em desenhos animados, histórias em quadrinhos e videogames que flertam com o insólito ou com a Ficção Científica.

O robô é descrito em termos técnicos - "Autômato Classe Norton 2.5 [...] na verdade era um Norton 2.6" (LEMOS, 2018, p.73) - e suas falas são mecânicas e inumanas: "Nenhum funcionário registrado da Sociedade Tecnocrata <IOIOOI> destrinchar seres/objetos" (LEMOS, 2018, p.74). Os demônios, por outro lado, são jocosos, violentos e, ao descobrirem a existência da personagem principal, já pensam em devorá-la: "Mas veja como está pálida e magra. A pele está descamada, o braço está destruído. Parece que está morta [...] Não dá pra comer" (LEMOS, 2018, p.74). A sua caracterização busca invocar a sensação de incômodo frequentemente encontrável nas cenas do conto: os demônios são descritos como "uma coisa magra e alta, cujo corpo era composto de turfa e raízes" (LEMOS, 2018, p.74); suas mãos são "secas, cheias de verrugas e calombos" (LEMOS, 2018, p.76); “aquele demônio era feio: olhos pequenos como duas bolinhas, cabelo ralo e seboso, a pele de um pálido esverdeado. Do nariz escorria um líquido viscoso" (LEMOS, 2018, p.77). O espaço onde os demônios habitam e trabalham reflete a decadência e devassidão deles:

Os dois demônios conduziram a Menininha por uma escada apodrecida até um compartimento escuro e fedendo a peixe podre. Vários vidros de conserva se amontoavam em prateleiras: compotas de fetos, olhos humanos, cascos fendidos, cabeças de cobra. Em barris maiores, macacos esfolados mergulhados em salmoura (um deles, a julgar pela expressão de terror, fora comido vivo e largado pela metade: só havia ossos da cintura pra baixo) (LEMOS, 2018, p.75-76)

O conto se descortina em um campo digno das narrativas mais extremas do Horror: sujeira, degeneração e a já apontada fragmentação dos corpos. O auge disso se encontra na descrição, mais detalhada, do corpo degradado da Menininha:

Mas Blefgar descobriu que o braço machucado não era o único problema da Menininha: costelas quebradas, duas pelo menos, formando uma elevação roxa como o manto da Papisa, contusões, arranhões, cortes perfurações que pareciam feitas à bala. Na área do coração havia uma enorme sutura, como se alguém tivesse costurado a carne após uma cirurgia. Estava inflamada, cheia de sangue 
e muco amarelado. Exalava um odor de queijo estragado. Em volta do corte, um pentagrama profundo feito com faca (LEMOS, 2018, p.77, grifo nosso)

O pentagrama - uma das mais tradicionais iconografias do Horror - desperta a atenção dos demônios, que passam a ver a Menininha com desconfiança. Nos parágrafos seguintes, as ameaças à integridade física e sexual da Menininha se mantêm, até chegarmos ao desfecho do conto. Descobrimos a origem da sua fome, que é explicada devido ao fato de que existe guardado - ou aprisionado? - dentro do corpo da menina um buraco negro que ameaça a tudo devorar. Esta é a revelação final que interrompe, de modo brusco e efetivo, a narrativa de "Menina bonita bordada de entropia”. A iconografia típica do Horror se mistura, sem qualquer mediação, à referência ao buraco negro, imagem tradicional das narrativas de FC, especialmente na vertente de aventuras interestelares. É desta lógica da aglutinação violenta de referentes estéticos diferentes entre si que o conto deriva boa parte do seu impacto New Weird.

"Menina bonita bordada de entropia", portanto, parece buscar um objetivo principal: criar no leitor a sensação de radical estranheza. O efeito insólito é prioridade em relação a outras dimensões possíveis de uma narrativa, sejam estas, por exemplo, a construção psicológica aprofundada de personagens, as peripécias de um enredo, ou um aprofundado debate político/ideológico. Lemos prioriza a construção deste mundo e as cenas de choque - seu conto é do tipo que se interessa, em primeiro lugar, sempre, pelo nocaute do sobrenatural. Para tanto, o universo desenvolvido no conto se calca fortemente em uma estética New Weird, enfatizando três das características principais do gênero: a mistura de vertentes do insólito (no caso, aqui, o Horror e a Ficção Científica), o uso da estética do grotesco e a dimensão política. A exploração literária dos dois espaços principais - o oceano e o navio - são menos importantes, porém ambos auxiliam tanto na mistura de gêneros, quanto na dimensão da narrativa New Weird.

Embora tenhamos acentuado que o principal alvo do conto seja a construção de um intenso efeito de estranheza, é possível também apontar que há uma dimensão política, ainda que de forma mais sutil se comparada a outras narrativas do estilo New 
Weird. Pedofilia, assassinato, abuso infantil, estupro - há algo sendo dito, em "Menina bonita bordada de entropia", sobre a violência infantil. A Menininha, embora longe de ser indefesa, está com frequência na posição de vítima. A violência psicológica que ela sofre nas mãos dos demônios é complementada pela sugestão da violência física sofrida pela personagem em épocas anteriores ao seu "resgate". Neste conto, a Ficção Científica e o Horror - embaladas na dança do New Weird - utilizam a imaginação para construir uma série de cenas que, além de impactarem o leitor, remetem indiretamente a uma denúncia acerca da violência dos adultos contra as crianças.

O trauma de Menininha é, então, uma dimensão subjacente ao conto. O buraco negro, guardado como arma secreta dentro da criança, seria uma alegoria do trauma? Ele é, em primeiro lugar, a imagem do puro insólito New Weird e tal imagem deve ser apreciada em sua autonomia estética. Contudo, devemos pensar nas marcas do abuso infantil e dos maus tratos domésticos como também integrantes da imagem da fome infinita, da escuridão que a tudo traga, da chaga nunca cicatrizada? Cercada de violência, a Menininha responde, ao final do conto, com um gesto também de violência, cuja consequência não é somente a aniquilação do agressor, como também o risco de obliteração da realidade como a conhecemos dentro do conto.

Assim, consideramos que "Menina bonita bordada de entropia" pode apontar para um interessante caminho dentro das vertentes do insólito na literatura brasileira contemporânea, com sua proposta de experimentalismo, compromisso político e quebra de regras pré-definidas das vertentes da Fantasia, Horror e Ficção Científica, tal como é proposto pelas conceituações do New Weird, um subgênero (até então) exclusivamente anglófono. 


\section{REFERÊNCIAS}

BAKHTIN, Mikhail. A cultura popular na Idade Média e no Renascimento: o contexto de François Rabelais. São Paulo: Editora Hucitec, 2010.

BRESSANE, Ronaldo. Los cibermonos de Locombia. IN: OLIVEIRA, Nelson de. Fractais tropicais: o melhor da ficção científica brasileira. São Paulo: Sesi-SP Editora, 2018.

CAUSO, R. de S. Ficção Científica, Fantasia e Horror no Brasil 1875 a 1950. Belo Horizonte: UFGM, 2003.

CLUTE, John. et al. The encyclopedia of Science Fiction (online). Disponível em: < http://www.sf-encyclopedia.com/>. Acesso em: 13 mai. 2021.

LEMOS, Cirilo. Menina bonita bordada de entropia. IN: OLIVEIRA, Nelson de. Fractais tropicais: o melhor da ficção científica brasileira. São Paulo: Sesi-SP Editora, 2018.

MALCOLM-CLARKE, Darja. Tracking phantoms. IN: VANDERMEER, Ann; VANDERMEER, Jeff. The New Weird. San Francisco: Tachyon Publications, 2008.

MATANGRANO, Bruno Anselmi; TAVARES, Enéias. Fantástico brasileiro: o insólito literário do romantismo ao fantasismo. Curitiba: Arte e Letra, 2018.

MENDLESOHN, F.; JAMES, E. Short Story of Fantasy. London: Middlesex University Press, 2009.

MIÉVILLE, China. A cidade e a cidade. São Paulo: Boitempo, 2014.

MIÉVILLE, China. Estação Perdido. São Paulo: Boitempo, 2016.

NOVELLO, Eric. Exorcismos, amores e uma dose de blues. São Paulo: Editora Gutenberg, 2014.

OLIVEIRA, Nelson de. Fractais tropicais: o melhor da ficção científica brasileira. São Paulo: Sesi-SP Editora, 2018.

ROAS, David. A ameaça do fantástico: aproximações teóricas. São Paulo: Editora Unesp, 2014.

VANDERMEER, Ann; VANDERMEER, Jeff. The new weird. San Francisco: Tachyon Publications, 2008.

VANDERMEER, Jeff. Aniquilação. Rio de Janeiro: Intrínseca, 2014. 